\title{
Evaluación de Tecnologías Sanitarias
}

\author{
MARIANELA CASTILLO-RIQUELME, MANUEL ANTONIO ESPINOZA S.
}

\section{I} a práctica clínica ha reconocido la evidencia como fuente esencial del proceso de toma de decisiones a nivel médico-paciente. A nivel central, en el otro extremo, la autoridad sanitaria responsable de la salud de la población también ha hecho este reconocimiento al momento de decidir cuáles intervenciones deben ser puestas a disposición de los médicos y pacientes. Esto ha sido explícito, por ejemplo, en la implementación de las "Garantías Explícitas en Salud" (GES), cuya canasta de prestaciones está sustentada por una revisión de la evidencia disponible. Sin embargo, a pesar de estos avances observados en los últimos años, Chile aún no cuenta con un proceso sistemático de evaluación de la evidencia relevante, incluyendo consideraciones económicas, sociales y legales, en un marco que asegure la legitimidad social de las decisiones sobre cobertura de nuevas y existentes intervenciones de salud.

La evaluación de tecnologías sanitarias (ETESA) corresponde a la investigación que examina las consecuencias técnicas, sociales, económicas, éticas y legales derivadas del uso de las tecnologías (o intervenciones) sanitarias, que se producen a corto y largo plazo y que pueden ser tanto directas como indirectas y tanto sobre los efectos deseados como sobre los indeseados. La ETESA, entendida como un área de trabajo multidisciplinario, ha tenido un gran desarrollo durante los últimos 20 años, lo que se ha plasmado en la implementación de agencias o institutos de ETESA en la mayoría de los países de ingresos altos en el mundo. La disyuntiva de priorizar entre tecnologías de salud y la proliferación cada vez más dinámica de nuevas tecnologías, que ejercen presión en los sistemas de salud para ser incluidas, afecta no sólo a países desarrollados. Esto ha llevado a que organismos internacionales estén promoviendo la implementación de ETESA en todos los países del orbe. En este contexto, Chile ha dado un paso importante en el reconocimiento de ETESA como política de salud a través de la creación de la Comisión Nacional de Evaluación de Tecnologías Sanitarias en diciembre de 2012, cuyo objetivo central es proponer un modelo de ETESA, con miras a ser implementado en Chile.

Es reconocido el rol que tienen los profesionales de la salud en determinar la demanda por cuidados de salud, pues en muchas ocasiones son ellos quienes determinan decisiones sobre qué debe ser incorporado al arsenal diagnóstico y terapéutico en los esquemas de cobertura financiera. Los médicos, enfermeras y otros profesionales de la salud, han desarrollado competencias en los procesos de evaluación de evidencia en los últimos 20 años, lo cual ha venido de la mano del desarrollo de la medicina basada en evidencia. Sin embargo, las decisiones de cobertura de tecnologías sanitarias requieren de consideraciones que van más allá de la efectividad y seguridad de dichas intervenciones. Estos elementos adicionales incluyen el costo de oportunidad de la asignación de recursos en salud (eficiencia) y la distribución de los resultados esperados (equidad), entre otros. Dada la importancia de estos elementos en el proceso de toma de decisiones y la necesidad por contar con profesionales de la salud capaces de tomar parte de esta discusión, es que resulta imprescindible informar y capacitar a profesionales de la salud en los procesos de ETESA.

La experiencia internacional indica que los profesionales que más han simpatizado con los procesos de ETESA son precisamente los clínicos, pues les otorga una herramienta validada y legítima para enfrentar sus decisiones a nivel de paciente, sin desatender consecuencias en otros pacientes. Esta herramienta es aún más valorada cuando profesionales de la salud toman cargos de gestión clínica y hospitalaria, y están forzados a tomar y/o implementar decisiones sobre cuidados de la salud. Por otro lado, un elemento central en el proceso de ETESA es la identificación de vacíos de información y el establecimiento de un juicio sobre la necesidad de asignar recursos a investigación, para resolver la incertidumbre que limita decisiones adecuadas en el sistema de salud. 
Debido a que muchos profesionales de la salud son además investigadores del área sanitaria, parece necesario que nuestros profesionales incorporen estos elementos adicionales en su quehacer como investigadores.

ETESA se ha desarrollado en el mundo desde comienzo de los años setenta y en la última década ha alcanzado mayor formalidad en Latinoamérica, en países como Brasil, México, Colombia y Uruguay. La cantidad de estudios de ETESA ha crecido en los últimos años y se espera que sigan aumentando, por la necesidad de evidencia que tendrán estas agencias. El alcance que ha tenido y está teniendo la ETESA en el desempeño de los sistemas de salud a nivel internacional, hacen necesario revisar y dar a conocer sus aspectos generales más relevantes a nuestra comunidad de profesionales de la salud. Esta es la motivación que dio origen a la presente serie de artículos, los cuales no pretenden atender en detalle todos los elementos de ETESA, sino que ofrecer un panorama general de los elementos fundamentales. Cada artículo revisa las bases conceptuales del tema y examina la experiencia internacional al respecto, para luego aterrizar los contenidos al contexto chileno identificando, en muchos casos, los desafíos pendientes.

Extendemos una cordial invitación a los profesionales de la salud, en especial a la comunidad médica de nuestro país a leer este suplemento y a involucrarse en el proceso de implementación de ETESA desde sus lugares de trabajo, sociedades científicas o representaciones gremiales. Es de esperar que los aspectos generales abordados en esta serie de artículos, sirvan como unificadores del lenguaje que esperamos hablar en un futuro cercano en los procesos de decisión vinculados a las tecnologías en salud. 